\title{
Thermodynamic and Kinetic Modeling of Cementitious Reactions in Lime-treated Clays
}

TASNEEM AHMADULLAH ${ }^{1}$, NEFELI MARIA BOMPOTI ${ }^{2}$ AND MARIA CHRYSOCHOOU ${ }^{1}$

${ }^{1}$ University of Connecticut

2261 Glenbrook Road

Presenting Author: tasneem.ahmadullah@uconn.edu

Treatment of clayey soils with cementitious agents including lime, Portland cement and pozzolanic by-products, is a widespread method for geotechnical and environmental stabilization purposes. While much progress has been made in quantifying and modeling cement hydration reactions, there is little corresponding data with respect to the pozzolan-clay systems [1]. A substantial difference between cement hydration and clay pozzolanic reactions is the slower dissolution rate of the clay minerals, requiring years to reach equilibrium compared to months in cement [1]. This study reports on the thermodynamics and kinetics of the cementitious reactions between two pure clay minerals (sodium bentonite and kaolinite) and slaked lime. The dissolution of the clay minerals and formation of calcium silicate hydrates and calcium aluminate hydrates are monitored over time in the solid by quantitative X-ray Diffraction, Thermogravimetric Analysis and solid-state Nuclear Magnetic Resonance. The pore solution of compacted, treated clay is extracted with a custom made apparatus and analyzed for major elements $(\mathrm{Ca}, \mathrm{Mg}, \mathrm{Al}, \mathrm{Si}$, $\mathrm{Fe}, \mathrm{Na}, \mathrm{K}$ and Total Inorganic Carbon). A thermodynamic and kinetic model of the system up to 180 days of reaction is developed on the basis of the solid and solution analysis data using the cement-based hydration model of Lothenbach et al. [3] as primary reference.

[1] De Windt L., Deneele D. and Maubec N. 2014. Kinetics of lime/bentonite pozzolanic reactions at 20 and $50{ }^{\circ} \mathrm{C}$ : Batch tests and modeling, Cement and Concrete Research, 59, 34-42.

[2] Chrysochoou M., 2014. Investigation of mineral dissolution rate and strength development in stabilized soils using quantitative X-ray Diffraction, Journal of Materials in Civil Engineering, 26(2), 288-295.

[3] Lothenbach B. and Winnefeld F. 2006. Thermodynamic modeling of the hydration of Portland Cement, Cement and Concrete Research, 36, 209-226. 